\title{
BMJ Global Health Using unannounced standardised patients to obtain data on quality of care in low-income and middle-income countries: key challenges and opportunities
}

Virginia Wiseman, ${ }^{\oplus 1,2}$ Mylene Lagarde, ${ }^{3}$ Roxanne Kovacs, ${ }^{2}$ Luh Putu Lila Wulandari, ${ }^{1}$ Timothy Powell-Jackson, ${ }^{2}$ Jessica King, ${ }^{2}$ Catherine Goodman, ${ }^{2}$ Kara Hanson, ${ }^{2}$ Rosalind Miller, ${ }^{2}$ Dong Xu, ${ }^{4}$ Marco Liverani, ${ }^{\oplus}$ Shunmay Yeung, ${ }^{5}$ Dumisani Hompashe, ${ }^{6}$ Mishal Khan, ${ }^{2}$ Ronelle Burger, ${ }^{7}$ Carmen S Christian, ${ }^{8}$ Duane Blaauw, ${ }^{9}$ On behalf of Members of the Standardised Patients Working Group

To cite: Wiseman V, Lagarde M, Kovacs R, et al. Using unannounced standardised patients to obtain data on quality of care in lowincome and middle-income countries: key challenges and opportunities. BMJ Global Health 2019;4:e001908. doi:10.1136/ bmjgh-2019-001908

Received 12 August 2019 Accepted 13 August 2019
Check for updates

(c) Author(s) (or their employer(s)) 2019. Re-use permitted under CC BY-NC. No commercial re-use. See rights and permissions. Published by BMJ

For numbered affiliations see end of article.

Correspondence to Dr Virginia Wiseman; virginia.wiseman@ishtm.ac.uk
Standardised patients (SPs) —also called patient actors, simulated patients or mystery clients-have a long history in medical education in high-income countries. ${ }^{1-5}$ They are now increasingly being used in low-income and middle-income countries (LMICs) to measure quality of care in a variety of clinical and retail (drug shop/pharmacy) settings. SPs are healthy people, or people with stable conditions, extensively trained to consistently simulate the medical history, physical symptoms and emotional characteristics of a real patient to multiple healthcare providers, and subsequently to report details of those interactions. The SP approach has been referred to as the 'gold standard' for capturing actual provider behaviour in the healthcare setting. ${ }^{6} 7$

In a paper published in BMJ Global Health, Kwan et al discussed the different types of research questions that can be addressed using SPs, and the various methodological and analytical issues to consider. ${ }^{8}$ In a recent complementary paper, King et al provide a stepby-step 'how to' guide for planning and implementing an SP study. ${ }^{9}$ The two papers, and the detailed field manual provided by Kwan $e t$ $a l$ in their appendix, combine to make a valuable set of resources for researchers using the SP method. In this commentary, members of the Standardised Patients Working Group, comprising economists, epidemiologists and social scientists across nine universities and global health institutions, elaborate on five key methodological and ethical issues raised in the two papers, and discuss how these can be assessed.

\section{SIMULATION}

A key concern about SPs is that they are not real patients and therefore provider responses to SPs may not be valid. Researchers using this method in LMICs go to considerable effort to train SPs to act as real patients. SPs receive coaching to build their understanding of the background story and presentation, including the body language of ill individuals ${ }^{10}$ - see the online supplementary appendix to the Kwan et al paper for examples of this process. Many studies also recruit SPs from the local communities where they are sent, as accents, language or other cultural characteristics are not easily replicated. ${ }^{11}$

Despite these efforts, concerns are often raised that providers may suspect that SPs are not genuine patients or carers. To allay these concerns, carefully designed studies include detection surveys where providers are contacted after an SP survey has been completed and asked about any suspected 'fake' patients (e.g. their symptoms, gender, age). In most studies, $5 \%$ or fewer of SPs are correctly suspected by providers of being 'fake' patients.

\section{TYPES OF CLINICAL CONDITIONS}

An important challenge with SPs is the scope of conditions that can be investigated. The SP method is only feasible for conditions that 
do not require physiological symptoms to be evident or invasive examinations to be performed: family planning request, cold, diarrhoea, tuberculosis or angina are examples of cases popular in SP studies in LMICs. ${ }^{9}$ However, the spread of mhealth technology may allow SPs to show providers 'faked' results on a mobile phone, and therefore, allow for an expansion of SP cases. ${ }^{12}$

Another challenge is that SPs do not typically complete follow-up visits, ${ }^{13}$ which excludes the assessment of continuity of care or chronic disease management. Studies from high-income countries highlight a 'first visit bias' that can skew assessment of quality. ${ }^{14} 15$ A study in the USA found that quality of care for gastritis and hip pain was higher in two successive consultations compared with the first one, leading the authors to conclude that quality of care is underestimated when only the first visit is considered, and that SPs are more appropriate for cases requiring 'definitive clinical action' at the first visit. ${ }^{16}$ While there are clear limits around the types of conditions that are suitable for SPs, the method has produced accurate measurements of the quality of care across a reasonably broad range of single encounters in LMIC settings. ${ }^{17}$ That being said, there is a need, to find ways to extend the SP method for multiple, sequential visits to the same provider for chronic conditions. ${ }^{89}$

\section{RECALL}

One of the reasons behind the growing enthusiasm for SPs in LMICs is the wealth of data that this approach can help collect. SPs are typically asked to complete a structured questionnaire or checklist shortly after their consultation, capturing details of their interaction with the provider including: how long did the consultation last? Which questions did the provider ask? Which physical examinations did they do? What advice did they give? Which treatment did they choose? All of this information is invaluable in settings where electronic medical records rarely exist and paper-based patient files contain minimal information. SPs are partly chosen on their ability to accurately memorise clinical interactions, are carefully trained to do this and have been found to be much better at remembering the consultation than actual patients. ${ }^{18} 19$

One approach to empirically assessing the accuracy of SP recall involves covert audio recording of the clinical interaction and comparing this with the SP's report. Concealed recorders have been successfully used in one study in India which showed high quality recall by SPs. ${ }^{17}$ However, the use of covert recording raises ethical issues and is limited to verbal communication. Another possible approach is for SPs to be accompanied by another fieldworker acting as a family member or friend, and to ask both individuals to answer independently the recall questions in order to measure inter-rater agreement.

\section{STANDARDISATION}

When comparing different types of providers, the SP approach can ensure comparability without concerns of patient selection issues, such as differences in patient socioeconomic characteristics (e.g., poorer patients more likely to consult public providers than private providers) or health status (e.g., sicker patients consulting more reputed providers). Standardisation allows researchers to alter one component of the patient-provider interaction at a time in order to estimate the causal impact of that component (e.g., estimating whether patient ethnicity has an impact on quality of care as investigated by Planas et al).$^{20}$ This ability to experiment with patient characteristics or attitudes is a key strength of the SP approach but researchers should also be alert to variations in the performance by SPs. Variation could arise if different individuals portray the same SP case in a different way, or if the same SP case is portrayed differently over time.

Measuring the consistency of SPs' portrayal of cases is done during training and sometimes during piloting (where SPs can be observed by a supervisor pretending to be a relative or friend), but it is more challenging during fieldwork. SP consistency can be measured indirectly by having multiple individuals portray the same medical case at the same healthcare provider. For instance, in their 2018 study using SPs to evaluate the quality of tuberculosis care in India, Kwan et $a l^{21}$ found that providers delivered relatively consistent care, repeating all observed actions, including mistakes, approximately $75 \%$ of the time. Further examination of the same dataset showed that almost none of the variation in outcomes was predicted by personal SP characteristics such as age, gender, height and weight, suggesting that SP portrayals were sufficiently standardised. ${ }^{6}$

\section{INFORMED CONSENT}

A major ethical concern surrounding SPs is the deception of healthcare providers and whether or not informed consent should be sought from them. Since the objective of SP studies is to understand the unfettered interaction between provider and client, it has been widely recognised that seeking informed consent from a provider can jeopardise the scientific validity of the study by influencing the decision of providers to take part (creating selection bias) or influencing their behaviour (Hawthorne effect) if they think SP visits are imminent. ${ }^{22} 23$

King et at discuss possible approaches to provider consent, such as obtaining consent well in advance to minimise Hawthorne effects, seeking consent from overarching authorities to minimise selection bias or obtaining a waiver of consent. Waivers of consent have been granted for minimally intrusive research in community pharmacies and other drug outlets ${ }^{1924}$ as well as a few large studies with providers. ${ }^{61}$ Since results are reported at the aggregate level, the benefits of SP studies including the provision of objective data on quality of care must be balanced against risks posed to individual providers and facilities. 


\section{CONCLUSION}

In summary, we would urge more research teams to report on the challenges and opportunities raised in this commentary. This information will enhance the uptake and generalisability of evidence from SP surveys and in turn, strengthen quality of care measurement in LMIC. Future investment in high-quality, accountable health systems relies on such information.

\section{Author affiliations}

${ }^{1}$ Kirby Institute, University of New South Wales, Sydney, New South Wales, Australia ${ }^{2}$ Department of Global Health and Development, Faculty of Public Health and Policy, London School of Hygiene and Tropical Medicine, London, UK

${ }^{3}$ Department of Health Policy, London School of Economics and Political Science, London, UK

${ }^{4}$ Sun Yat-sen Global Health Institute, School of Public Health, Sun Yat-sen University, Guangzhou, China

${ }^{5}$ Department of Clinical Research, Faculty of Infectious and Tropical Diseases, London School of Hygiene \& Tropical Medicine, London, UK

${ }^{6}$ Department of Economics, University of Fort Hare, Alice, South Africa

${ }^{7}$ Department of Economics, Stellenbosch University, Matieland, South Africa

${ }^{8}$ Department of Economics, University of the Western Cape, Cape Town, South Africa

${ }^{9}$ Centre for Health Policy, University of Witwatersrand, Johannesburg, South Africa

Contributors All authors contributed to the ideas behind this commentary. VW, $M L$, RK and LPLW developed the first draft of this commentary and all remaining authors contributed to subsequent drafts.

Funding The authors have not declared a specific grant for this research from any funding agency in the public, commercial or not-for-profit sectors.

Competing interests None declared.

Patient consent for publication Not required.

Provenance and peer review Commissioned; internally peer reviewed.

Data availability statement № additional data is available.

Open access This is an open access article distributed in accordance with the Creative Commons Attribution Non Commercial (CC BY-NC 4.0) license, which permits others to distribute, remix, adapt, build upon this work non-commercially, and license their derivative works on different terms, provided the original work is properly cited, appropriate credit is given, any changes made indicated, and the use is non-commercial. See: http://creativecommons.org/licenses/by-nc/4.0/.

\section{REFERENCES}

1. Barrows HS, Abrahamson S. The programmed patient: a technique for appraising student performance in clinical neurology. J Med Educ 1964;39:802-5.

2. Rutherford-Hemming T, Alfes CM, Breymier TL. A systematic review of the use of standardized patients as a simulation modality in nursing education. Nurs Educ Perspect 2019;40:84-90.

3. Smithson J, Bellingan M, Glass B, et al. Standardized patients in pharmacy education: an integrative literature review. Curr Pharm Teach Learn 2015;7:851-63.

4. Wallace P. Following the threads of an innovation: the history of standardized patients in medical education. Caduceus 1997;13:5-28.
5. Wilbur K, Elmubark A, Shabana S. Systematic review of standardized patient use in continuing medical education. $J$ Contin Educ Health Prof 2018;38:3-10.

6. Daniels B, Kwan A, Satyanarayana S, et al. Use of standardised patients to assess gender differences in quality of tuberculosis care in urban India: a two-city, cross-sectional study. Lancet Glob Health 2019;7:e633-43.

7. Das J, Holla A, Das V, et al. In urban and rural India, a standardized patient study showed low levels of provider training and huge quality gaps. Health Aff 2012;31:2774-84.

8. Kwan A, Daniels B, Bergkvist S, et al. Use of standardised patients for healthcare quality research in low-income and middle-income countries. BMJ Glob Health 2019;4:e001669.

9. King JJC, Das J, Kwan A, et al. How to do (or not to do) ... using the standardized patient method to measure clinical quality of care in LMIC health facilities. Health Policy Plan 2019. doi:10.1093/heapol/ czz078. [Epub ahead of print: 19 Aug 2019].

10. Daniels B, Dolinger A, Bedoya G, et al. Use of standardised patients to assess quality of healthcare in Nairobi, Kenya: a pilot, crosssectional study with international comparisons. BMJ Glob Health 2017;2: 000333 .

11. Christian CS, Gerdtham U-G, Hompashe D, et al. Measuring quality gaps in TB screening in South Africa using standardised patient analysis. Int J Environ Res Public Health 2018;15. doi:10.3390/ ijerph15040729

12. Gottschalk F, Mimra W, Waibel C. Health services as Credence goods: a field experiment. SSRN 2018.

13. Sylvia $\mathrm{S}$, Xue $\mathrm{H}$, Zhou $\mathrm{C}$, et al. Tuberculosis detection and the challenges of integrated care in rural China: a cross-sectional standardized patient study. PLoS Med 2017;14:e1002405.

14. Beullens J, Rethans JJ, Goedhuys J, et al. The use of standardized patients in research in general practice. Fam Pract 1997;14:58-62.

15. Luck J, Peabody JW. Using standardised patients to measure physicians' practice: validation study using audio recordings. BMJ 2002;325.

16. Tamblyn RM, Klass DJ, Schnabl GK, et al. Sources of unreliability and bias in standardized-patient rating. Teach Learn Med 1991;3:74-85.

17. Das J, Kwan A, Daniels B, et al. Use of standardised patients to assess quality of tuberculosis care: a pilot, cross-sectional study. Lancet Infect Dis 2015;15:1305-13.

18. Glassman PA, Luck J, O'Gara EM, et al. Using standardized patients to measure quality: evidence from the literature and a prospective study. Jt Comm J Qual Improv 2000;26:644-53.

19. Satyanarayana S, Kwan A, Daniels B, et al. Use of standardised patients to assess antibiotic dispensing for tuberculosis by pharmacies in urban India: a cross-sectional study. Lancet Infect Dis 2016;16:1261-8.

20. Planas M-E, García PJ, Bustelo M, et al. Effects of ethnic attributes on the quality of family planning services in Lima, Peru: a randomized crossover trial. PLoS One 2015;10:e0115274.

21. Kwan A, Daniels B, Saria V, et al. Variations in the quality of tuberculosis care in urban India: a cross-sectional, standardized patient study in two cities. PLoS Med 2018;15:e1002653.

22. Fitzpatrick A, Tumlinson K. Strategies for optimal implementation of simulated clients for measuring quality of care in low- and middleincome countries. Glob Health Sci Pract 2017;5:108-14.

23. Tabernero $P$, Parker M, Ravinetto R, et al. Ethical challenges in designing and conducting medicine quality surveys. Trop Med Int Health 2016;21:799-806.

24. Miller R, Goodman C. Do chain pharmacies perform better than independent pharmacies? Evidence from a standardised patient study of the management of childhood diarrhoea and suspected tuberculosis in urban India. BMJ Glob Health 2017;2. 